\title{
Article
}

\section{Rumination, event centrality, and perceived control as predictors of post- traumatic growth and distress: The Cognitive Growth and Stress model}

Brooks, Matthew, Graham-Kevan, Nicola, Lowe, Michelle and Robinson, Sarita Jane

Available at https://clok.uclan.ac.uk/17595/

Brooks, Matthew orcid iconORCID: 0000-0002-5469-7769, Graham-Kevan, Nicola orcid iconORCID: 0000-0003-0621-3093, Lowe, Michelle and Robinson, Sarita Jane orcid iconORCID: 0000-0002-4237-5412 (2017) Rumination, event centrality, and perceived control as predictors of post-traumatic growth and distress: The Cognitive Growth and Stress model. British Journal of Clinical Psychology, 56 (3). pp. 286-302. ISSN 0144-6657

It is advisable to refer to the publisher's version if you intend to cite from the work. http://dx.doi.org/10.1111/bjc.12138

For more information about UCLan's research in this area go to http://www.uclan.ac.uk/researchgroups/ and search for <name of research Group>.

For information about Research generally at UCLan please go to http://www.uclan.ac.uk/research/

All outputs in CLoK are protected by Intellectual Property Rights law, including Copyright law. Copyright, IPR and Moral Rights for the works on this site are retained by the individual authors and/or other copyright owners. Terms and conditions for use of this material are defined in the policies page. 
Running head: THE COGNITIVE GROWTH AND STRESS MODEL

Rumination, centrality and control as predictors of posttraumatic growth and distress:

The Cognitive Growth and Stress model

Brooks, M.*a , Graham-Kevan, N. ${ }^{\mathrm{a}}$, Lowe, M. ${ }^{\mathrm{b}}$, \& Robinson, S. ${ }^{\mathrm{a}}$

*Corresponding author: Matthew Brooks, School of Psychology, University of Central

Lancashire, Preston, Lancashire, PR1 2HE, UK. Email: mbrooks1@uclan.ac.uk .

\author{
Author affiliations: \\ ${ }^{a}$ School of Psychology, University of Central Lancashire, Preston, UK \\ ${ }^{\mathrm{b}}$ School of Education and Psychology, University of Bolton, UK
}




\begin{abstract}
Objectives: The Cognitive Growth and Stress (CGAS) model draws together cognitive processing factors previously untested in a single model. Intrusive rumination, deliberate rumination, present and future perceptions of control and event centrality were assessed as predictors of posttraumatic growth and posttraumatic stress.
\end{abstract}

Method: The CGAS model is tested on a sample of survivors $(N=250)$ of a diverse range of adverse events using structural equation modelling techniques.

Results: Overall, the best fitting model was supportive of the theorised relations between cognitive constructs, and accounted for $30 \%$ of the variance in posttraumatic growth and $68 \%$ of the variance in posttraumatic stress across the sample.

Conclusions: Rumination, centrality and perceived control factors are significant determinants of positive and negative psychological change across the wide spectrum of adversarial events. In its first phase of development, the CGAS model also provides further evidence of the distinct processes of growth and distress following adversity.

Keywords: cognitive processing; event centrality; perceived control; posttraumatic growth; posttraumatic stress; rumination 


\section{Practitioner points}

Clinical implications

- People can experience positive change after adversity, regardless of life background or types of events experienced.

- While growth and distress are possible outcomes after adversity, they occur through distinct processes.

- Support or intervention should consider rumination, event centrality and perceived control factors to enhance psychological well-being.

\section{Cautions/limitations}

- Longitudinal research would further clarify the findings found in this study.

- Further extension of the model is recommended to include other viable cognitive processes implicated in the development of positive and negative changes after adversity. 
The emotional impact of adversarial events, such as assault, combat and natural disasters, can not only lead to negative psychological changes, but also opportunities for positive transformation, collectively known as posttraumatic growth (PTG; Linley \& Joseph, 2004; Tedeschi \& Calhoun, 2004). PTG can arise in the aftermath of adversity, comprising the ability to go beyond prior psychological functioning. Survivors demonstrating PTG typically report greater appreciation of life, greater personal strength, improved interpersonal relationships, a new life philosophy and spiritual development (Tedeschi \& Calhoun, 2004).

The processes underlying PTG are described in models of positive change (JanoffBulman, 2006; Joseph \& Linley, 2005), the most prominent being that of Tedeschi and Calhoun (2004). Within their model, growth emerges through cognitive attempts to reconcile shattered beliefs about the controllability and predictability of the world. These life narratives are valuable because they provide a framework to derive meaning from events. Theoretically, growth occurs in the event of a significant challenge to core beliefs about the world and the self. Such challenges trigger cognitive processing that manages initial distress, but can evolve into concentrated efforts leading to PTG.

Difficulties processing memories in the aftermath of adverse events may lead to posttraumatic stress (PTS). PTS manifests in survivors who experience avoidant behaviours, intrusive thoughts, hyperarousal and negative alterations in cognitions or mood extending beyond a one-month period (American Psychological Association, 2013). According to cognitive interpretations, symptoms arise through threatening event-appraisals, changes in memory functioning, negative cognitions or prior beliefs about the world (Brewin \& Holmes, 2003). The transformational model (Tedeschi \& Calhoun, 2004) therefore conceptualises PTG and PTS as both processes and outcomes associated with adversarial struggles.

Models have started to map pathways towards growth and distress. Such attempts have involved tracing the entire process outlined in the transformational theory (Triplett, 
Tedeschi, Cann, Calhoun, \& Reeve, 2012), and exploring shared and unique predictors of PTG and PTS (Lancaster, Klein, Nadia, Szabo, \& Mogerman, 2015). However, the aforementioned models are limited, relying on regression-based techniques which do not control for measurement error (Kline, 2016), and not accounting for other variables associated with psychological adjustment after adversity, such as event centrality and control perceptions.

\section{The Cognitive Growth and Stress model}

This research expands upon specific tenets of the transformational theory (Tedeschi \& Calhoun, 2004) by incorporating cognitive constructs into a model to explain PTG and PTS (see Figure 1). The study explores interrelationships between theoretically-derived growth concepts as well as those rarely explored in the PTG literature.

Insert Figure 1 about here

A central concept when understanding adjustment after adversity is the impact on control perceptions. Subjective interpretations of event controllability are of particular interest to researchers (e.g. Frazier et al., 2011). Cognitive processing theories imply that adverse events challenge subjective feelings of control (Ehlers \& Clark, 2000), which are met with attempts to reassert control over one's behaviour, environment and life events (Frazier \& Caston, 2015). A lack of control is therefore viewed as an inhibitor to the processing of adverse events (Joseph \& Linley, 2005).

While definitions of control exist in the literature (see Skinner, 1996), one aspect that has received attention is the temporal dimension. According to this interpretation (Frazier, 
Berman, \& Steward, 2002), control perceptions take three forms in the aftermath of an adverse event and differentially relate to adjustment: past control refers to whether a person feels they had control over an event, and is generally unrelated to adjustment (Frazier et al., 2011); present control is how an individual responds to a current event, and is associated with better adjustment regardless of adversity type or frequency (Frazier \& Caston, 2015); future control refers to the extent to which an individual believes they have control over an event reoccurring. Like present control, increased future control perceptions are associated with enhanced psychological functioning (Frazier et al., 2002), and negatively related with depression and hopelessness (Clements, Sabourin, \& Spiby, 2004).

Event controllability is traditionally explored in the context of distress, where perceptions of present and future control are negatively related to psychological outcomes, such as PTS (Frazier et al., 2002). These two aspects of control may be relevant to studying positive change, which has not yet elucidated relationships with PTG. The literature contends that PTG relates to enhanced mastery and control (Dekel, Mandl, \& Solomon, 2011), with present control over one's current circumstances positively associated with PTG. Similarly, future control may also be positively related to PTG, such that overcoming previous adversity will reinforce perceptions that future events are also more controllable. Therefore, exploring how present and future aspects of control relate to PTG may provide opportunities to expand the transformational model (Tedeschi \& Calhoun, 2004).

Cognitive responses to adversity involve a degree of rumination. A passive focus on the causes and consequences of events is associated with poor psychological functioning, and attempts to suppress thoughts about the stressor by engaging in other activities (NolenHoeksema, 1991; Nolen-Hoeksema, Wisco, \& Lyuboirsky, 2008). However, rumination can 
serve adaptive functions, such as a coping strategy to manage emotional responses (Papageorgiou \& Wells, 2001), or to generate alternative paths toward previously unobtainable goals (Ciarocco, Vohs, \& Baumeister, 2010).

Distinctions between rumination types are made within the growth literature (Allbaugh, Wright, \& Folger, 2016; Cárdenas, Martínez, \& Abarca, 2016; Stockton, Hunt \& Joseph, 2011). Intrusive rumination refers to automatic and unwanted thoughts or memories of the adverse event. Intrusive rumination may prime more conscious efforts to understand the impact of the adverse event, known as deliberate rumination (Tedeschi \& Calhoun, 2004). The differential impact of both types of rumination on PTG is recognised; increased levels of intrusive rumination are related to greater distress, while increased deliberate rumination is associated with positive change (Morris \& Shakespeare-Finch, 2011). Although it is acknowledged that intrusive ruminations precede deliberate efforts, it remains unclear how intrusive rumination lays foundations for problem-focused attempts to deal with the event, and ultimately PTG. This process may be explained through other mediating variables absent within the transformational model (Tedeschi \& Calhoun, 2004), such as event centrality.

Event centrality is understood as the degree to which people exposed to an adverse event define themselves in part or exclusively as someone who has experienced adversity (Groleau, Calhoun, Cann, \& Tedeschi, 2013). Highly central events can become an anchoring point in an individual's life-story and a reference point for future inferences (Berntsen \& Rubin, 2006). Paradoxically, centrality uniquely predicts both distress and growth (Groleau et al., 2013), which underscores the need to further understand its conceptual nature. Notably, few studies explore how event centrality relates to other post-event cognitions associated with PTG or PTS. For example, centrality can mediate between cognitive responses across a range of event types (Fitzgerald, Berntsen, \& Broadbridge, 2016), by making memories of adverse events more accessible, which then prompt other cognitive processes conducive of growth, 
such as life-narrative organisation (Boals, 2010). Growth then occurs when the event is assimilated into the survivor's perspective of themselves and the world (Lancaster et al., 2015).

The proposed Cognitive Growth and Stress (CGAS) model will simplify complex relationships among cognitive factors responsible for growth and distress. There is little research on relationships between rumination and perceived control, although rumination could occur in the absence of control (Wänke \& Schmid, 1996). It may be that the less control people feel over current and over future events, the more they tend to ruminate. This process triggers PTS symptoms, but also deliberate attempts to understand the meaning of the adverse event. Conversely, survivors with higher control perceptions are less likely to experience intrusive rumination or PTG, as a significant challenge to control perceptions may not have occurred (Tedeschi \& Calhoun, 2004).

The CGAS model posits relationships between centrality and rumination. Evidence indicates that centrality is closely aligned with rehearsal and ruminative processes that are focused on negative and self-relevant aspects of the event (Boals \& Schuettler, 2011; NolenHoeksema et al., 2008). Additionally, the adaptiveness of rumination is considered flexible and context-dependent (Bonanno, Pat-Horenczyk \& Noll, 2011). Therefore, the extent to which an adverse event becomes fundamental to one's identity may influence rumination adaptiveness. As central events serve to attribute meaning to experiences (Berntsen \& Rubin, 2006), the CGAS model theorises that centrality motivates a shift from distressing thoughts to deliberate forms of rumination that bring about positive shifts in world view. Specifically, increased levels of intrusive rumination lead to the event becoming part of a survivor's identity, which sets in motion cognitive processes associated with the development of both PTG and PTS. While distressing, highly central events may be processed in more meaningful ways, due to their relative importance to the individual. 
The CGAS model also determines relationships between centrality and control perceptions that are largely unexamined. Arguably, highly central events result from significant challenges to control perceptions that lead a person to focus on aspects of their life that may be explained by the adversity (Boals \& Schuettler, 2011; Janoff-Bulman, 2006). Attributional theories (e.g. Janoff-Bulman, 1979) posit that uncontrollable views of the event aftermath arise as a result of internalised, stable and global attributions. Such attributional styles mean that survivors with low control perceptions experience memories of the event as being ingrained within their self-identity. This is reflected in the CGAS model, which proposes that both present and future control perceptions are negatively related to event centrality. The degree to which current and future events are perceived to be controllable, and their subsequent impact on one's sense of identity, may explain differential outcomes after adversity.

\section{Aims of study}

The CGAS model expands transformational theory (Tedeschi \& Calhoun, 2004) by identifying cognitive pathways towards PTG and PTS through relationships between intrusive rumination, deliberate rumination, event centrality, present control and future control. It is expected that present and future control are positively associated to one another as they fall within the temporal dimension of control. As the experience of adversity can challenge control perceptions, present and future control will negatively predict event centrality as the adversity becomes assimilated into one's self-identity. It is also expected that a lack of present and future control will predict intrusive rumination. Increased intrusive thoughts will then positively predict centrality as the event becomes internalised, which then leads to deliberate rumination. Based on existing literature, it is hypothesised that intrusive 
rumination will positively predict PTS and initiate more deliberate forms of rumination, which will positively predict PTG. Finally, as growth may reflect attempts to regain mastery and control, both present and future control are hypothesised to positively predict PTG, and therefore negatively predict PTS.

\section{Method}

\section{Participants}

Given that previous research has shown that PTG and PTS can be reported across a range of events and populations (Brooks, Lowe, Graham-Kevan \& Robinson, 2016; Linley \& Joseph, 2004; Ozer, Best, Lipsey \& Weiss, 2003), the current study includes a diverse range of people exposed to adversity. Participants were a self-selecting sample of 250 people (74.4\% female) recruited via university-wide online bulletins $(36.4 \%)$, victim services (32.8\%) and professional networks (30.8\%) from northwest England. The mean age of participants was 35.21 years $(S D=13.41)$, ranging from 16 to 79 years. The majority of the sample were heterosexual $(83.2 \%)$ and White $(88.0 \%)$, with less than half identifying as religious (48.0\%). Nearly two-thirds of participants were single or dating (64.9\%). All participants had at least one prior exposure to an adverse event; the majority (82.5\%) experiencing more than one event. Three-quarters of the sample (75.2\%) were exposed to intentional adversity involving physical or sexual abuse, sexual assault, rape, military conflict or neglect. Characteristics of the sample are presented in Table 1.

Insert Table 1 about here

\section{Materials}


Adverse experiences. The Posttraumatic Diagnostic Scale (PDS; Foa, Cashman, Jaycox, \& Perry, 1997) includes a self-report checklist of 12 adverse events, including natural disasters, physical or sexual assault, and bereavement. An additional item was added in this study to account for neglect. Participants record the frequency of each event to the best of their memory. The PDS has been validated for use in samples exposed to a wide range of adversity (Foa et al., 1997).

Event centrality. The Centrality of Events Scale (CES; Berntsen \& Rubin, 2006) is a measure of the extent to which an individual feels a particular event has become part of their identity. The short version used in this study demonstrates similar reliability to the full 20 item version (Berntsen \& Rubin, 2006) and consists of seven items rated on a scale from 0 (totally disagree) to 4 (totally agree). Example items include, "I feel the event has become part of my identity", and "This event has permanently changed my life". Higher scores on the CES suggest the event is more central to the survivor's life story. The CES demonstrated excellent reliability in the current study $(\alpha=.92)$.

Rumination. Intrusive and deliberate rumination was measured using the Event Related Rumination Inventory (ERRI; Cann et al., 2011). Intrusive thoughts are assessed by 10 items regarding unwanted thoughts about the event, such as "I could not keep images or thoughts about the event from entering my mind". Ten additional items measure deliberate attempts by a survivor to understand the event, with items such as, "I thought about whether I have learned anything as a result of my experience". For both subscales, participants rate the extent to which they agree with the statements on a scale from 0 (not at all) to 3 (often), with higher scores endorsing more ruminative tendencies. The ERRI has been shown to display good construct validity (Cann et al., 2011). Reliability for the ERRI intrusive $(\alpha=.96)$ and deliberate $(\alpha=.93)$ subscales was excellent in the current study. 
Perceived control. The Perceived Control Over Stressful Events Scale (PCOSES; Frazier et al., 2011) is a 17-item questionnaire that assesses temporal aspects of control regarding a specific adverse event. The measure has three subscales of past, present and future control, rated on a scale from 0 (strongly disagree) to 3 (strongly agree), with higher scores on any given subscale reflecting greater perceived control. As past control is unrelated to adjustment (Frazier \& Caston, 2015), only the present and future subscales were used in this study. Items include, "How I deal with this event is now under my control” (present control) and "I have no control over whether a similar event happens again" (future control). The PCOSES demonstrates good validity, test-retest reliability and internal consistency (Frazier et al., 2011), which was replicated for the present $(\alpha=.79)$ and future control $(\alpha=$ .80) subscales in this study.

Posttraumatic growth. The Posttraumatic Growth Inventory-Short Form (PTGI-SF; Cann et al., 2010) is a 10-item measure of positive changes in response to a specific life event. Using a six-point scale from 0 (no change) to 5 (very great change), participants rate the extent to which they have changed following their experience with items such as, "I changed my priorities about what is important in life" and "I discovered that I'm stronger than I thought I was". A total score is obtained, with higher scores indicating greater perceived growth. The PTGI-SF has been validated among survivors of domestic violence, bereavement and complex health conditions, with similar reliability to the full 21 -item version (Cann et al., 2010). The measure demonstrated high internal consistency in the current study $(\alpha=.87)$.

Posttraumatic stress. The PTSD-8 (Hansen et al., 2010) is a screening measure of PTS symptoms. Using a scale from 0 (not at all) to 3 (all the time), eight items assess the triad of avoidant, hyperarousal and intrusion symptoms, with higher scores endorsing more PTS symptoms. Example items include, "Avoiding activities that remind you of the event" 
(avoidance), "Feeling on guard" (hyperarousal), and "Recurrent thoughts or memories of the event" (intrusion). The PTSD-8 has been validated on survivors of accidents, natural disasters and rape (Hansen et al., 2010). Initially, the overall scale demonstrated unacceptable reliability $(\alpha=.38)$, however, the removal of two intrusive items greatly improved consistency $(\alpha=.90)$. The six-item version was thus used for the remaining analyses.

\section{Procedure}

Study procedures were approved by the university ethics committee. Participants accessed an online study which informed them about the nature of the research and issues related to confidentiality and withdrawal. The participants nominated one adverse event of their choice and responded to all questions according to their symptoms in the past two weeks. Upon completion of the survey, participants were debriefed and provided with the contact details of relevant support services.

\section{Data analysis}

Hypotheses were examined in three phases, using SPSS (version 23) and AMOS (version 23) with maximum likelihood estimation. The first phase evaluated the measurement model through confirmatory factor analysis (CFA) according to established procedures (Kline, 2016). Intrusive rumination, deliberate rumination, event centrality, present control, future control, PTG and PTS were represented by latent constructs, with items from the measures serving as indicators. The unobservable latent constructs are conceptualised according to the sample realisation interpretation (Bollen, 2002), a flexible and inclusive definition considering such variables as not fully present, yet estimated from information within the data. For the second phase, direct relationships between the latent variables were 
examined. Third, mediation analysis was conducted to determine the presence of indirect effects within the model, using Sobel tests (Sobel, 1982).

Reliability and validity was assessed in the measurement model (Hair, Black, Babin, \& Anderson, 2010). Convergent validity was examined using the Average Variance Extracted (AVE), which determines the extent to which the indicator variables represent the latent construct; values should ideally exceed .50. Discriminant validity was assessed by the Maximum Shared Variance (MSV) and Average Shared Squared Variance (ASV). MSV values should fall below that of the AVE, and the ASV should exceed the correlations between the latent variables, indicating that the constructs are empirically distinct (Hair et al., 2010). Indicators loading greater than .60 were considered to represent the latent factor well (Kline, 2016). Modification indices were then inspected to determine further improvements to model fit.

The model was evaluated using several fit indices recommended in SEM guidelines (Hu \& Bentler, 1999). While the $\chi^{2}$ was computed, it is sensitive to sample size and so the $\chi^{2} / d f$ ratio, Akaike Information Criterion (AIC), Comparative Fit Index (CFI), TuckerLewis index (TLI), Root Mean Square Error of Approximation (RMSEA) and Standardised Root Mean Square Residual (SRMR) were calculated. In respect of the $\chi^{2} / d f$ ratio, a value of less than 2 represents good model fit (Hair et al., 2010). The AIC compares the parsimony of the model relative to other models, with smaller values desirable (Kline, 2016). The CFI, TLI, RMSEA and SRMR are advantageous in that they are less influenced by sample size and model complexity. Guidelines (Hu \& Bentler, 1999) suggest the CFI and TLI indices exceed .90 in order for the model to be an acceptable fit of the data, with values above .95 indicating a good fit; RMSEA and SRMR values should lie below .08 and .06 , respectively. 


\section{Results}

Descriptive and correlational statistics

Descriptive statistics and correlations among the CGAS model factors are presented in Table 2. PTG was positively related to deliberate rumination, present control, and future control. PTG and PTS were positively related to event centrality, in the hypothesised direction, along with intrusive and deliberate rumination. Event centrality negatively correlated with present control. Both present and future control were positively associated with one another. While present control was negatively related to PTS, intrusive and deliberate rumination, future control was associated with PTG only. The target PTG and PTS variables were unrelated.

Insert Table 2 about here

\section{Structural equation modelling}

Measurement properties were examined with reliability and validity statistics, reported for the final model in Table 3. The seven constructs displayed excellent composite reliability and discriminant validity. Aside from present control and PTG, all other variables were well-represented by their indicators. The PCOSES and PTGI-SF are relatively new measures and limited validation studies exist, and so the convergent validity of the present control and PTG latent factors was improved by removing indicators of low loading $(<.60$; Hair et al., 2010). Four items on the present control latent variable and two items on the PTG latent variable were removed, leaving the latent factors with more than the required minimum of three indicators for SEM analyses (Kline, 2016). The AVE of both constructs improved but fell below the recommended .50 , although this index is noted as a conservative measure 
of convergent validity (Malhotra \& Dash, 2011). However, all seven latent variables were well-represented by their indicators (all at $p<.001$ ).

Insert Table 3 about here

Five refinements to the baseline structural model were made to improve parsimony and model fit. Fit indices are reported at each stage in Table 4. The initial model was a poor representation of the data, with CFI and TLI indices below the recommended minimum .90 cut-offs (Hu \& Bentler, 1999). The removal of weak factor loadings in the second model greatly improved the AIC, CFI, TLI and SRMR, with the $\chi^{2} / d f$ and RMSEA indicating better fit. In the third model, modification indices suggested two pairs of error terms on the PTG latent variable and a further pair on the deliberate rumination factor that could be correlated to improve model fit. Examination of the individual error items suggested they were sufficiently close in meaning to explain the covariance, and thus correlating the terms was reasonable in keeping with the sample realisation interpretation of latent variables (Bollen, 2002; Hair et al., 2010). As a result, the $\chi^{2} / d f$, AIC, CFI and TLI indices revealed a structural model that more accurately reflected the data.

In the fourth model, modification indices revealed that one deliberate rumination item on the ERRI was confounded with another item on the CES. To simplify interpretation of the model, the ERRI item was removed as this demonstrated greater improvements to the AIC, CFI and RMSEA confidence intervals. Furthermore, as it was expected that the intrusive items on the PTSD-8 might be confounded with the ERRI intrusive rumination subscale, a fifth refinement to the model was tested with the PTS latent variable consisting of only the 
avoidance and hyperarousal items. This model revealed similar fit indices to model four, with no significant changes to paths and relationships between latent variables. In the sixth model, non-significant paths were removed, lowering the AIC index. This model was deemed to be final, based on improved parsimony and fit indices.

Overall, the final CGAS structural model accounted for $30 \%$ of the variance in PTG and $68 \%$ of the variance in PTS across the sample, and is presented in Figure 2. In line with the hypothesis, both present and future control factors were positively related to one another. Present control positively predicted PTG and negatively predicted intrusive rumination and event centrality. Contrary to the hypothesis, future control predicted PTG, but not PTS. Intrusive rumination was a positive predictor of PTS and deliberate rumination; however, deliberate rumination did not predict PTG. In line with the hypotheses, event centrality was a positive predictor of PTG, PTS and deliberate rumination, and was strongly predicted by present control and intrusive rumination.

Insert Table 4 about here

\section{Mediation analysis}

Analysis of indirect effects using Sobel tests indicated that intrusive rumination mediated the negative relationship between present control and event centrality $(z=-3.12, p$ $=.001)$, and the negative relationship between present control and PTS $(z=-4.97, p<.001)$. Event centrality also mediated the positive relationship between intrusive and deliberate rumination $(z=2.82, p<.001)$, and the positive association between intrusive rumination and $\operatorname{PTS}(z=2.60, p=.009)$. 


\section{Discussion}

This paper presents the CGAS model of pathways towards growth and distress in its first developmental phase. While rumination, centrality and control are key determinants of psychological adjustment after adversity (e.g. Frazier \& Caston, 2015; Groleau et al., 2013; Morris \& Shakespeare-Finch, 2011), this study differs from existing models by drawing these concepts together into one framework. Notably, the model identified the most appropriate relationships between cognitive processing variables. In line with other research (Dekel et al., 2011), the study suggested that PTG and PTS are both possible outcomes after adversity that arise through distinct processes. The overlap in the determinants of adjustment indicates that some degree of distress is a necessary part of the process of PTG, but the non-significant correlation between PTG and PTS reveals that an absence of distress does not necessarily equate to higher growth, or vice-versa (Tedeschi \& Calhoun, 2004).

The findings offer support to elements of the transformational PTG model (Tedeschi \& Calhoun, 2004). Increased intrusive ruminations were associated with heightened distress, even after controlling for intrusive aspects of PTS. These intrusive thoughts preceded more deliberate attempts to contemplate the wider significance of the event, consistent with the idea that the content of the rumination can determine psychological outcomes (Stockton et al., 2011). Contrary to expectations, deliberate rumination was positively associated with, but did not predict, PTG. It is acknowledged that PTG is a function of the degree to which the survivor is cognitively engaged with the event (Tedeschi \& Calhoun, 2004). Research suggests that deliberate rumination alone only serves to reassess the event, while positive 
reappraisal involves a reorientation necessary for growth to occur (Cárdenas et al., 2016). Therefore, survivors in this study were possibly able to contemplate some good in the event, but had not yet experienced positive shifts in world view that enabled the reconstruction of new meaning.

Findings confirmed that event centrality robustly predicted growth and distress (Allbaugh et al., 2016; Groleau et al., 2013). Notably, the CGAS model went further to observe the ability of centrality to mediate between types of rumination, and between intrusive rumination and PTS. This finding is supported in recent literature that views centrality as a facilitator of other cognitive processes after adversity, in part due to the increased accessibility of salient memories (Fitzgerald et al., 2016; Lancaster et al., 2015). Centralised events create internal, stable and global attributions, leading the survivor to believe their adversity is related to personal characteristics (Berntsen \& Rubin, 2006). The current research, however, suggests that centrality can have adaptive effects on psychological adjustment, by motivating more constructive forms of rumination and providing a context from which control perceptions are increased. This is important as literature (e.g. Ehlers \& Clark, 2000) has traditionally viewed intrusions as reflecting an inability to process the adverse experience, thus perpetuating PTS symptoms, rather than an event that has become overly central to one's identity which may lead to PTG.

A unique contribution of the CGAS model to the understanding of cognitive processing after adversity was the inclusion of control perceptions that are currently lacking in other PTG and PTS models (e.g. Ehlers \& Clark, 2000; Tedeschi \& Calhoun, 2004). Generally, present control perceptions were more strongly related to other modelled variables than future control. Indeed, of all three temporal domains, present control is most closely associated with adjustment (Frazier et al., 2011), suggesting that survivors were primarily concerned with their current response to the event, rather than taking preventative steps to 
avoid reoccurrence. However, both present and future control positively predicted PTG, consistent with a forward-looking orientation (Frazier \& Caston, 2015). Positive transformation is therefore experienced when the survivor regains control over their recovery, associated with increased mastery and self-efficacy within the growth process (Tedeschi \& Calhoun, 2004).

\section{Implications and limitations}

The CGAS model highlights the role of event centrality and control perceptions in the development of PTG and PTS. Until recently, these factors have received scant attention, and are not explicitly acknowledged within existing models (e.g. Ehlers \& Clark, 2000; Tedeschi $\&$ Calhoun, 2004). Future research should confirm the direction and nature of relationships observed here to further understand the role these factors play in enabling people to experience positive and negative change.

Important therapeutic implications arise from the CGAS model, which has clinical utility by encouraging clinician recognition that adjustment after adversity is neither solely positive nor negative. Clinicians may target specific cognitions that enhance control perceptions as part of the rebuilding of the assumptive world (Janoff-Bulman, 2006), guide survivors towards more constructive ruminative processes and being aware of central event valance, which has the potential to lead to both growthful and distressing outcomes.

The CGAS model is advantageous in being applicable across diverse events and survivors. Existing models normally focus on one specific type of adversity (e.g. Morris \& Shakespeare-Finch, 2011) or are limited by their reliance on undergraduate samples (Lancaster et al., 2015; Triplett et al., 2012). This study extends existing findings to the wider spectrum of people exposed to diverse adverse events, yet confirm the conclusions of other PTG and PTS studies (e.g. Groleau et al., 2013; Lancaster et al., 2015; Triplett et al., 2012), 
thus providing rigor to the findings. Future developments to the CGAS model should consider other cognitive and affective processes applicable across other events and populations. One potential avenue could explore the indirect role of positive reappraisal on the relationship between deliberate rumination and PTG.

While the findings contribute to the understanding of cognitive processing after adversity, the study is not without limitation. Even though SEM has statistical advantages, the cross-sectional design means that true causal directionality cannot be determined, and longitudinal studies are warranted. Additionally, it is recognised that not all theoretically viable paths were estimated, although the model was parsimonious and aligned with SEM principles (Kline, 2016). Finally, while fit indices exceeded those in other published studies (e.g. Triplett et al., 2012), the CFI and TLI values lacked robustness relative to existing criteria (Hu \& Bentler, 1999), thus caution is required. Nevertheless, acceptable variance in PTG and PTS was revealed, considering the diverse population and types of events included.

\section{Conclusion}

The CGAS model provides greater understanding of the cognitive processes involved in the development of PTG and PTS. While supportive of the transformational model (Tedeschi \& Calhoun, 2004), this research further identifies specific relationships between control perceptions, ruminative types and event centrality. The study recognises that cognitive responses to adversity are complex, entailing both positive and negative sequelae that are differentially related to growth and distress. Findings from this model can target specific cognitions that promote psychological well-being and identify those who are struggling to recover from adverse events. 


\section{References}

Allbaugh, L. J., Wright, M. O. D., \& Folger, S. F. (2016). The role of repetitive thought in determining posttraumatic growth and distress following interpersonal trauma. Anxiety, Stress, \& Coping, 29, 21-37. doi: 10.1080/10615806.2015.1015422

American Psychological Association (2013). Diagnostic and statistical manual of mental disorders ( $5^{\text {th }}$ ed.). Washington, DC: American Psychological Association.

Berntsen, D., \& Rubin, D. C. (2006). The centrality of event scale: A measure of integrating a trauma into one's identity and its relation to post-traumatic stress disorder symptoms. Behaviour Research and Therapy, 44, 219-231. doi: 10.1016/j.brat.2005.01.009

Boals, A. (2010). Autobiographical memories that have become central to identity: Gender differences in the Centrality of Events Scale for positive and negative events. Applied Cognitive Psychology, 24, 107-121. doi: 10.1002/acp.1548

Boals, A., \& Schuettler, D. (2011). A double-edged sword: Event centrality, PTSD and posttraumatic growth. Applied Cognitive Psychology, 25, 817-822. doi: 10.1002/acp.1753

Bollen, K. A. (2002). Latent variables in psychology and the social sciences. Annual Review of Psychology, 53, 605-634. doi: 10.1146/annurev.psych.53.100901.135239

Bonanno, G. A., Pat-Horenczyk, R., \& Noll, J. (2011). Coping flexibility and trauma: The Perceived Ability to Cope with Trauma (PACT) scale. Psychological Trauma: Theory, Research, Practice, and Policy, 3, 117-129. doi: 10.1037/a0020921

Brewin, C. R., \& Holmes, E. A. (2003). Psychological theories of posttraumatic stress disorder. Clinical Psychology Review, 23, 339-376. doi:10.1016/S02727358(03)00033-3 
Brooks, M., Lowe, M., Graham-Kevan, N., \& Robinson, S. (2016). Posttraumatic growth in students, crime survivors and trauma workers exposed to adversity. Personality and Individual Differences, 98, 199-207. doi: 10.1016/j.paid.2016.04.051

Cann, A., Calhoun, L. G., Tedeschi, R. G., Taku, K., Vishnevsky, T., Triplett, K. N., \& Danhauer, S. C. (2010). A short form of the Posttraumatic Growth Inventory. Anxiety, Stress, \& Coping, 23, 127-137. doi: 10.1080/10615800903094273

Cann, A., Calhoun, L. G., Tedeschi, R. G., Triplett, K. N., Vishnevsky, T., \& Lindstrom, C. M. (2011). Assessing posttraumatic cognitive processes: The Event Related Rumination Inventory. Anxiety, Stress, \& Coping, 24, 137-156. doi: $10.1080 / 10615806.2010 .529901$

Cárdenas, C. M., Martínez, M. A., \& Abarca, X. F. (2016). Deliberate rumination and positive reappraisal as serial mediators between life impact and posttraumatic growth in victims of state terrorism in Chile (1973-1990). Journal of Interpersonal Violence, 1-17. doi: $10.1177 / 0886260516642294$

Ciarocco, N. J., Vohs, K. D., \& Baumeister, R. F. (2010). Some good news about rumination: Task-focused thinking after failure facilitates performance improvement. Journal of Social and Clinical Psychology, 29, 1057-1073. doi: 10.1521/jscp.2010.29.10.1057

Clements, C. M., Sabourin, C. M., \& Spiby, L. (2004). Dysphoria and hopelessness following battering: The role of perceived control, coping, and self-esteem. Journal of Family Violence, 19, 25-36. doi: 10.1023/B:JOFV.0000011580.63593.96

Dekel, S., Mandl, C., \& Solomon, Z. (2011). Shared and unique predictors of posttraumatic growth and distress. Journal of Clinical Psychology, 67, 241-252. doi: 10.1002/jclp.20747 
Ehlers, A., \& Clark, D. M. (2000). A cognitive model of posttraumatic stress disorder. Behaviour Research and Therapy, 38, 319-345. doi: 10.1016/S0005-7967(99)00123-0

Fitzgerald, J. M., Berntsen, D., \& Broadbridge, C. L. (2016). The influences of event centrality in memory models of PTSD. Applied Cognitive Psychology, 30, 10-21. doi: 10.1002/acp.3160

Foa, E. B., Cashman, L., Jaycox, L., \& Perry, K. (1997). The validation of a self-report measure of posttraumatic stress disorder: The Posttraumatic Diagnostic Scale. Psychological Assessment, 9, 445-451. doi: 10.1037/1040-3590.9.4.445

Frazier, P., Berman, M., \& Steward, J. (2002). Perceived control and posttraumatic stress: A temporal model. Applied and Preventive Psychology, 10, 207-223. doi: 10.1016/S0962-1849(01)80015-9

Frazier, P., \& Caston, J. (2015). Event controllability moderates the relation between perceived control and adjustment to stressors. Journal of Loss and Trauma, 20, 526540. doi: 10.1080/15325024.2014.949161

Frazier, P., Keenan, N., Anders, S., Perera, S., Shallcross, S., \& Hintz, S. (2011). Perceived past, present, and future control and adjustment to stressful life events. Journal of Personality and Social Psychology, 100, 749-765. doi: 10.1037/a0022405

Groleau, J. M., Calhoun, L. G., Cann, A., \& Tedeschi, R. G. (2013). The role of centrality of events in posttraumatic distress and posttraumatic growth. Psychological Trauma: Theory, Research, Practice, and Policy, 5, 477-483. doi: 10.1037/a0028809

Hair, J. F., Black, W. C., Babin, B. J., \& Anderson, R. E. (2010). Multivariate data analysis ( $7^{\text {th }}$ ed.). Upper Saddle River, NJ: Pearson Education International. 
Hansen, M., Andersen, T. E., Armour, C., Elklit, A., Palic, S., \& Mackrill, T. (2010). PTSD8: A short PTSD inventory. Clinical Practice \& Epidemiology in Mental Health, 6 , 101-108. doi: 10.2174/1745017901006010101

Hu, L. T., \& Bentler, P. M. (1999). Cutoff criteria for fit indexes in covariance structure analysis: Conventional criteria versus new alternatives. Structural Equation Modelling: A Multidisciplinary Journal, 6, 1-55. doi: 10.1080/10705519909540118

Janoff-Bulman, R. (1979). Characterological versus behavioral self-blame: inquiries into depression and rape. Journal of Personality and Social Psychology, 37, 1798-1809. doi: 10.1037/0022-3514.37.10.1798

Janoff-Bulman, R. (2006). Schema-change perspectives on posttraumatic growth. In L. G. Calhoun and R. G. Tedeschi (Eds.) Handbook of posttraumatic growth: Research and practice (pp. 81-99). Mahwah, NJ: Erlbaum.

Joseph, S., \& Linley, P. A. (2005). Positive adjustment to threatening events: An organismic valuing theory of growth through adversity. Review of General Psychology, 9(3), 262280. doi: 10.1037/1089-2680.9.3.262

Kline, R. B. (2016). Principles and practice of structural equation modelling (4 ${ }^{\text {th }} \mathrm{ed}$.). New York, NY: Guildford Press.

Lancaster, S. L., Klein, K. R., Nadia, C., Szabo, L., \& Mogerman, B. (2015). An integrated model of posttraumatic stress and growth. Journal of Trauma \& Dissociation, 16, 399-418. doi: 10.1080/15299732.2015.1009225

Linley, P. A., \& Joseph, S. (2004). Positive change following trauma and adversity: A review. Journal of Traumatic Stress, 17, 11-21. doi: 10.1023/B:JOTS.0000014671.27856.7e 
Malhotra, N. K., \& Dash, S. (2011). Marketing research: An applied orientation. New Delhi: Pearson Publications.

Morris, B. A., \& Shakespeare-Finch, J. (2011). Rumination, posttraumatic growth, and distress: structural equation modelling with cancer survivors. Psycho-Oncology, 20, 1176-1183. doi: 10.1002/pon.1827

Nolen-Hoeksema, S. (1991). Responses to depression and their effects on the duration of depressive episodes. Journal of Abnormal Psychology, 100, 569-582. doi: $10.1037 / 0021-843 X .100 .4 .569$

Nolen-Hoeksema, S., Wisco, B. E., \& Lyubomirsky, S. (2008). Rethinking rumination. Perspectives on Psychological Science, 3, 400-424. doi: 10.1111/j.17456924.2008.00088.x

Ozer, E. J., Best, S. R., Lipsey, T. L., \& Weiss, D. S. (2003). Predictors of posttraumatic stress disorder and symptoms in adults: a meta-analysis. Psychological Bulletin, 129, 52-73. doi: 10.1037/0033-2909.129.1.52

Papageorgiou, C., \& Wells, A. (2001). Metacognitive beliefs about rumination in recurrent major depression. Cognitive and Behavioral Practice, 8, 160-164. doi: $10.1016 / \mathrm{S} 1077-7229(01) 80021-3$

Skinner, E. A. (1996). A guide to constructs of control. Journal of Personality and Social Psychology, 71, 549-570. doi: 10.1037/0022-3514.71.3.549

Sobel, M. E. (1982). Asymptotic confidence intervals for indirect effects in structural equation models. Sociological Methodology, 13, 290-312. doi: 10.2307/270723

Stockton, H., Hunt, N., \& Joseph, S. (2011). Cognitive processing, rumination, and posttraumatic growth. Journal of Traumatic Stress, 24, 85-92. doi:10.1002/jts.20606 
Tedeschi, R. G., \& Calhoun, L. G. (2004). Posttraumatic growth: Conceptual foundations and empirical evidence. Psychological Inquiry, 15, 1-18. doi: 10.1207/s15327965pli1501_01

Triplett, K. N., Tedeschi, R. G., Cann, A., Calhoun, L. G., \& Reeve, C. L. (2012). Posttraumatic growth, meaning in life, and life satisfaction in response to trauma. Psychological Trauma: Theory, Research, Practice, and Policy, 4, 400-410. doi: $10.1037 / \mathrm{a} 0024204$

Wänke, M., \& Schmid, J. (1996). Rumination: When all else fails. In R. S. Wyer (Ed.), Ruminative thoughts: Advances in social cognition (pp. 177-187). Mahwah, NJ: Erlbaum. 


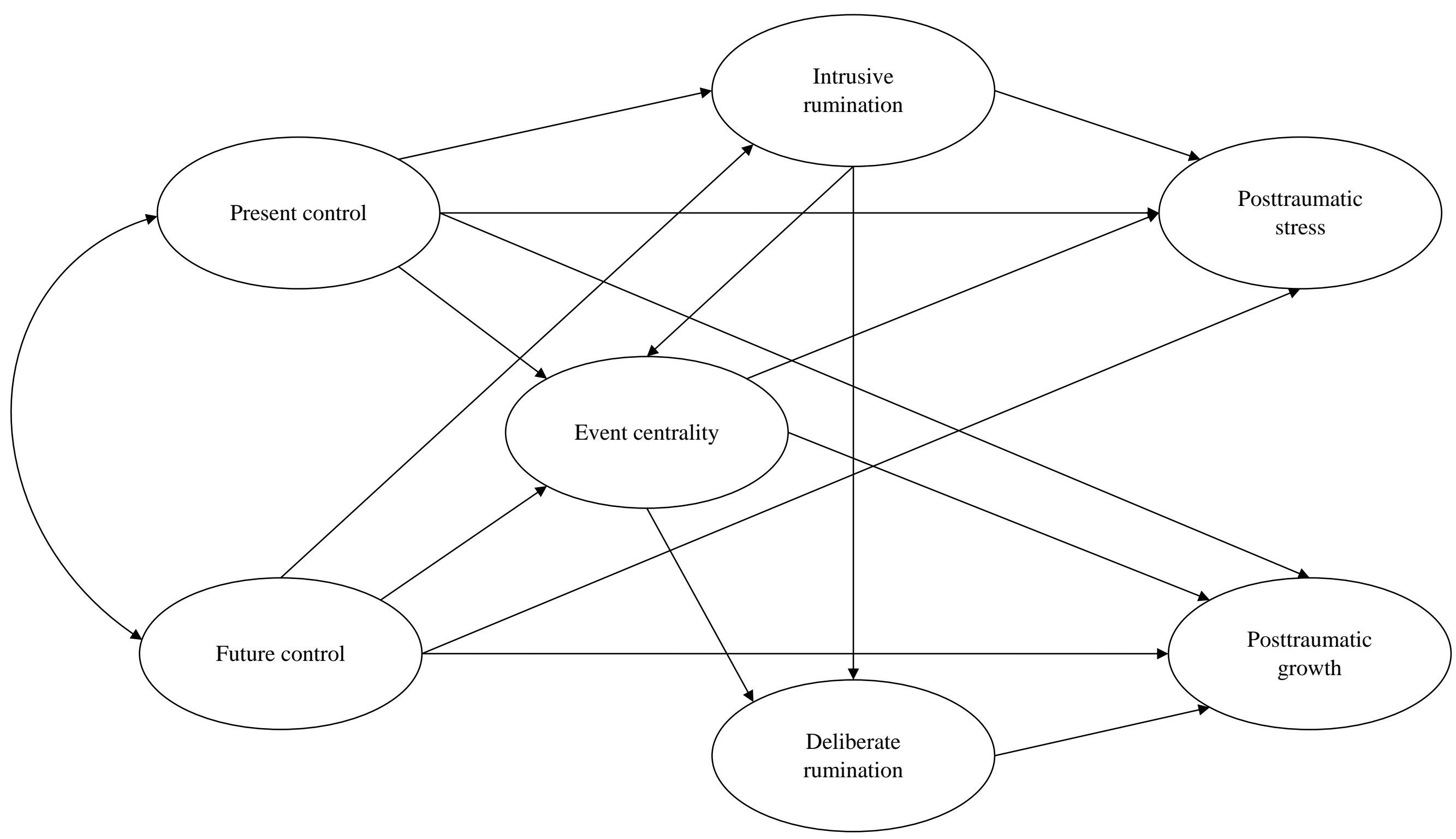

Figure 1. Hypothesised Cognitive Growth and Stress model. 
Table 1.

Sample and adversarial event exposure characteristics.

\begin{tabular}{|c|c|c|c|}
\hline Characteristic & $M$ & $S D$ & Range \\
\hline Age at serious event (years) & 20.21 & 12.01 & $1-57$ \\
\hline Time since serious event (years) & 15.00 & 13.83 & $1-61$ \\
\hline \multirow[t]{2}{*}{ Number of event types experienced } & 3.73 & 2.49 & $1-9$ \\
\hline & & $N$ & $\%$ \\
\hline \multicolumn{4}{|l|}{ Event type } \\
\hline Accident & & 116 & 46.4 \\
\hline Natural disaster & & 22 & 8.8 \\
\hline Serious attack/threat by partner & & 69 & 27.6 \\
\hline Serious attack/threat by other & & 112 & 44.8 \\
\hline Child sexual abuse & & 74 & 29.6 \\
\hline Rape by partner & & 31 & 12.4 \\
\hline Rape by other & & 37 & 14.8 \\
\hline Imprisonment & & 21 & 8.4 \\
\hline Military conflict & & 19 & 7.6 \\
\hline Serious illness & & 57 & 22.8 \\
\hline Bereavement & & 121 & 48.4 \\
\hline Neglect & & 69 & 27.6 \\
\hline Other event & & 58 & 23.2 \\
\hline
\end{tabular}


Table 2.

Descriptive data and correlations between variables in the final structural model after item removal $(N=250)$.

\begin{tabular}{|c|c|c|c|c|c|c|c|c|c|c|c|c|c|}
\hline Variable & $M$ & $S D$ & Min. & Max. & Skewness & Kurtosis & 1 & 2 & 3 & 4 & 5 & 6 & 7 \\
\hline 1. Event centrality & 18.78 & 7.76 & 0 & 28 & -.87 & -.15 & - & & & & & & \\
\hline 2. Intrusive rumination & 13.72 & 9.42 & 0 & 30 & .10 & -1.26 & $.58 * * *$ & - & & & & & \\
\hline 3. Deliberate rumination & 11.51 & 8.06 & 0 & 27 & .19 & -1.15 & $.48 * * *$ & $.62 * * *$ & - & & & & \\
\hline 4. Present control & 6.28 & 2.76 & 0 & 12 & -.07 & -.32 & $-.35 * * *$ & $-.40 * * *$ & -.11 & - & & & \\
\hline 5. Future control & 6.42 & 3.22 & 0 & 12 & -.21 & -.59 & -.01 & .00 & .07 & $.22 * *$ & - & & \\
\hline 6. Posttraumatic stress & 8.11 & 5.57 & 0 & 18 & .11 & -1.22 & $.50 * * *$ & $.73 * * *$ & .10 & $-.37 * * *$ & .05 & - & \\
\hline 7. Posttraumatic growth & 19.95 & 9.77 & 0 & 40 & -.10 & -.78 & $.25 * * *$ & .04 & $.20 * *$ & $.20 * *$ & $.24 * * *$ & .02 & - \\
\hline
\end{tabular}

Note. $* p<.05, * * p<.01, * * * p<.001$. 
Table 3.

CFA reliability and validity statistics for the seven latent variables in the final model.

\begin{tabular}{lcccc}
\hline \multicolumn{1}{c}{ Variable } & Composite reliability & AVE & MSV & V AVE \\
\hline 1. Event centrality & .92 & .61 & .36 & .78 \\
2. Intrusive rumination & .96 & .71 & .70 & .84 \\
3. Deliberate rumination & .93 & .58 & .41 & .76 \\
4. Present control & .73 & .43 & .22 & .65 \\
5. Future control & .80 & .50 & .10 & .71 \\
6. Posttraumatic stress & .89 & .58 & .70 & .76 \\
7. Posttraumatic growth & .86 & .45 & .08 & .67 \\
\hline
\end{tabular}


Table 4.

Summary of fit indices for models tested.

\begin{tabular}{|c|c|c|c|c|c|c|c|c|c|c|}
\hline \multirow[b]{2}{*}{ Model } & \multirow[b]{2}{*}{ df } & \multirow[b]{2}{*}{$\chi^{2}$} & \multirow[b]{2}{*}{$\chi^{2} / \mathrm{df}$} & \multirow[b]{2}{*}{ AIC } & \multirow[b]{2}{*}{ CFI } & \multirow[b]{2}{*}{ TLI } & \multirow[b]{2}{*}{ SRMR } & \multirow[b]{2}{*}{ RMSEA } & \multicolumn{2}{|c|}{ RMSEA $90 \%$ CI } \\
\hline & & & & & & & & & Low & High \\
\hline 1. Initial baseline model & 1415 & $2417.23 * * *$ & 1.71 & 2667.23 & .89 & .88 & .08 & .05 & .05 & .06 \\
\hline 2. Low loading items removed & 1112 & $1906.40 * * *$ & 1.71 & 2132.40 & .90 & .90 & .08 & .05 & .05 & .06 \\
\hline 3. Appropriate error terms correlated & 1106 & $1728.72 * * *$ & 1.56 & 1966.72 & .93 & .92 & .07 & .05 & .05 & .06 \\
\hline 4. ERRI deliberate item removed & 1059 & $1617.09 * * *$ & 1.53 & 1851.09 & .93 & .93 & .07 & .05 & .04 & .05 \\
\hline 5. Intrusive PTSD-8 items removed & 926 & $1431.17 * * *$ & 1.55 & 1649.17 & .93 & .93 & .07 & .05 & .04 & .05 \\
\hline 6. Non-significant paths removed ${ }^{1}$ & 929 & $1424.73 * * *$ & 1.53 & 1646.57 & .93 & .93 & .07 & .05 & .04 & .05 \\
\hline
\end{tabular}

Note. $* * * p<.001 .{ }^{1}$ The PTSD-8 intrusive items were re-introduced in this model. 


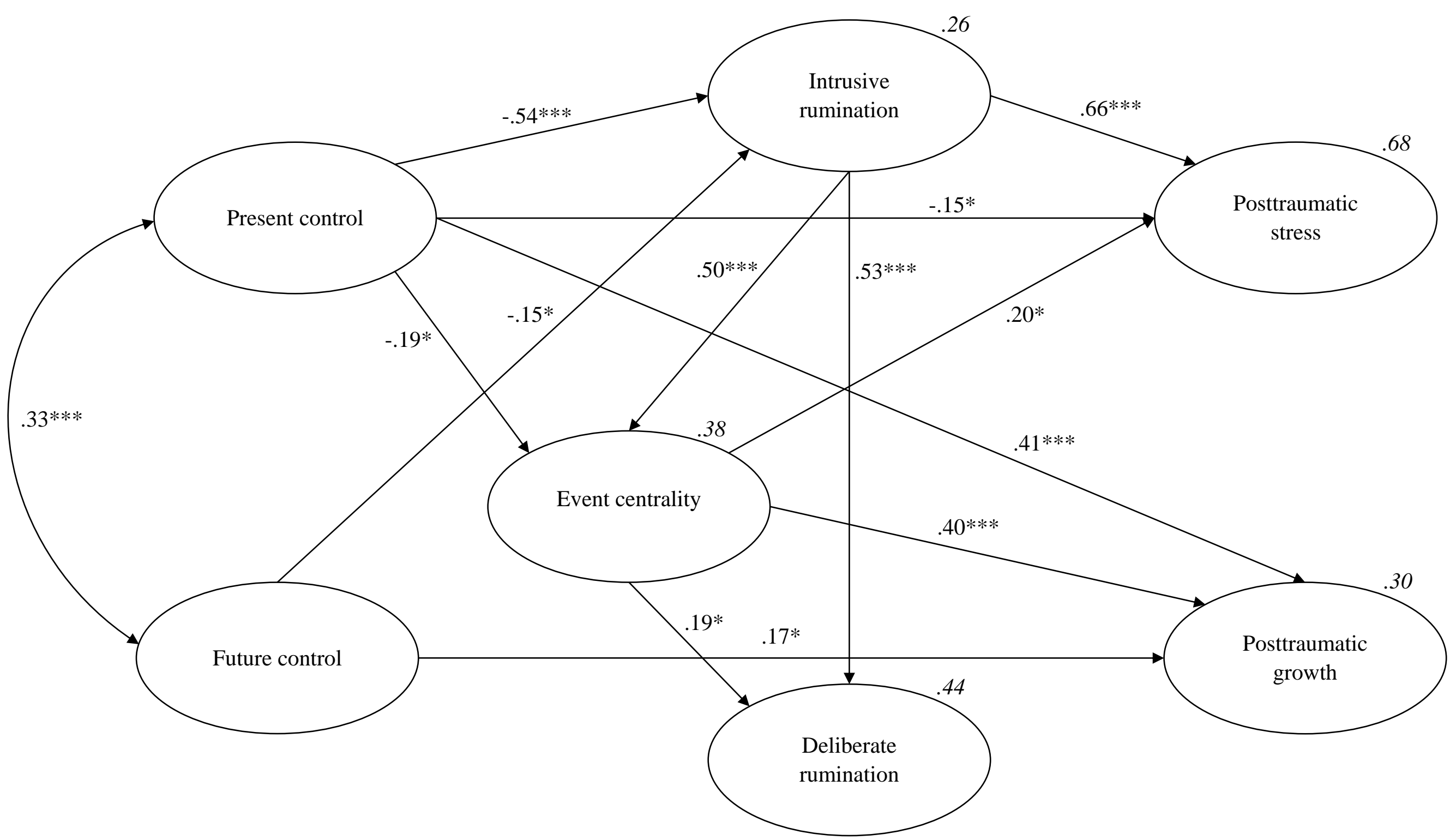

Figure 2. Standardised solution for the final CGAS model. $R^{2}$ for each endogenous variable is shown in italics. Observed variables, error terms and non-significant paths are not included for simplicity. $* p<.05, * * p<.01, * * * p<.001$. 